\title{
HUBUNGAN PANJANG BERAT DAN FAKTOR KONDISI IKAN LIMBAT (Clarias nieuhofii) YANG TERTANGKAP PADA BUBU KAWAT DI PERAIRAN RAWA RIMBO ULU KABUPATEN TEBO PROVINSI JAMBI
}

\author{
Yudha Maulana Syuhada ${ }^{1}$ Rini Hertati $^{2^{*}}$ Muhammad Natsir Kholis $^{2}$ \\ ${ }^{1}$ Mahasiswa Jurusan Pemanfaatan Sumberdaya Perikanan Fakultas Perikanan, \\ Universitas Muara Bungo-Jambi \\ ${ }^{2}$ Staf Pengajar Jurusan Pemanfaatan Sumberdaya Perikanan Fakultas Perikanan, \\ Universitas Muara Bungo-Jambi \\ *Email: rinihertati4@gmail.com
}

\begin{abstract}
ABSTRAK
Penelitian ini dilaksanakan pada Bulan Juni sampai Agustus 2020 di perairan rawa desa sukamaju. Tujuan penelitian ini yaitu untuk mengetahui pola pertumbuhan dan faktor kondisi ikan limbat (Clarias nieuhofii) yang tertangkap pada bubu kawat di perairan rawa desa sukamaju Kecamatan Rimbo Ulu Kabupaten Tebo Provinsi Jambi. Metode yang digunakan dalam penelitian ini adalah metode survei dengan teknik ekperimental fishing. Hasil penelitian menunjukan bahwa ikan limbat (Clarias nieuhofii) memiliki pola pertumbuhan allometrik negatif, dimana pertumbuhan panjang lebih cepat dari pada pertumbuhan berat. Sedangkan faktor kondisi didapatkan nilai $\mathrm{K}=1,01$ yang artinya ikan limbat yang tertangkap dalam kondisi baik.
\end{abstract}

Kata Kunci : Faktor Kondisi, Ikan Limbat, Jambi, Pola Pertumbuhan, Rimbo Ulu,

\begin{abstract}
This research was conducted from June to August 2020 in the swamp waters of the Sukamaju village. The purpose of this study was to determine the growth patterns and condition factors of limbate fish (Clarias nieuhofii) caught in wire traps in the Swamp Waters of Sukamaju Village, Rimbo Ulu District, Tebo Regency, Jambi Province. The method used in this research is a survey method with experimental fishing techniques. The results showed that limbate fish (Clarias nieuhofii) had a negative allometric growth pattern, where the length growth was faster than the weight growth. While the condition factor obtained a value of $K=1.01$, which means that the fish caught in good condition.
\end{abstract}

Keywords: Condition Factors, Clarias nieuhofii, Jambi, Growth Patterns, Rimbo Ulu 


\section{PENDAhuluan \\ Latar Belakang}

Perikanan merupakan salah satu sumber pendapatan bagi masyarakat di Kabupaten Tebo, karena Kabupaten Tebo memiliki perairan cukup potensial untuk pengembangan perikanan melalui perairan umum dan daratan. Salah satu alat penangkapan ikan yang banyak digunakan nelayan di Kabupaten Tebo yaitu dari jenis bubu. Prinsip dasar dari bubu adalah menjebak penglihatan ikan sehingga ikan tersebut terperangkap di dalamnya. Alat ini sering diberi nama fishing pots atau fishing basket (Brandt, 1984). Teknologi penangkapan menggunakan bubu banyak dilakukan di negara-negara yang menengah maupun maju (Martasuganda, 2005).

Nelayan Kabupaten Tebo biasanya menggunakan alat tangkap bubu kawat untuk menangkap ikan limbat (Clarias nieuhofii). Ikan ini merupakan sejenis ikan lele yang bertubuh panjang dan umumnya kekuning-kuningan. Ikan ini menyebar luas di asia tenggara termasuk di semenanjung Malaysia, Indonesia (Jawa, Sumatera, dan Kalimantan) hingga Filipina. Penamaan jenis ikan ini dapat berbeda-beda disetiap wilayah seperti di Kabupaten Kampar Provinsi Riau disebut ikan limbek, Provinsi Jambi disebut ikan lembat,

\section{METODE PENELITIAN}

\section{Waktu dan Tempat}

Penelitian dilakukan di perairan rawa desa sukamaju Kecamatan Rimbo Ulu Kabupaten Tebo Provinsi Jambi (Gambar 1). Penelitian ini dilaksanakan selama 3 bulan yaitu dari Bulan Juni sampai Agustus 2020.
DKI Jakarta dikenal sebagai ikan lindi, Provinsi Bengkulu disebut ikan kli sungai dan lainnya (Https://id.wikipedia.org/wiki/Limbat). Informasi biologis ikan limbat sangat penting guna untuk melestarikan sumberdaya ikan ini dari kepunahan. Banyak cara melestarikannya seperti: konservasi, budidaya, domestikasi, pola pertumbuhan dan hubungan panjang berat ikan (Syafrialdi , 2020). Salah satu cara melestarikan ikan limbat di desa sukamaju Kecamatan Rimbo Ulu yaitu dengan melihat hubungan dan berat ikan limbat yang tertangkap pada alat tangkap bubu kawat. Sebenarnya data hubungan panjang dan berat ikan ini dapat digunakan sebagai dasar menentukan biomassa dalam mengestimasi produksi stok ikan (Smith, 1996; Kholis et al., 2018). Selain itu pengukuran panjang dan berat yang dihubungkan dengan umur dapat memberikan informasi tentang komposisi stok, umur, matang gonad, mortalitas, siklus hidup dan pertumbuhan (Fatioye dan Oluajo, 2005; Kholis et al., 2018). Tujuan dari penelitian ini adalah untuk mengetahui pola pertumbuhan ikan limbat (Clarias nieuhofii) dan faktor kondisinya diperairan rawa desa sukamaju Kecamatan Rimbo Ulu Kabupaten Tebo Provinsi Jambi. 
yang berfungsi sebagai alat tangkap untuk menangkap ikan limbat, penggaris $30 \mathrm{~cm}$ digunakan untuk mengukur panjang tubuh ikan limbat, timbangan digital platfoarm scale digunakan untuk menimbang berat tubuh ikan limbat, kertas label untuk penandaan, kain lap untuk membersihkan peralatan dan kamera untuk dokumentasi. Bahan yang digunakan dalam penelitian adalah ikan limbat dan umpan yang digunakan pada alat tangkap bubu kawat.
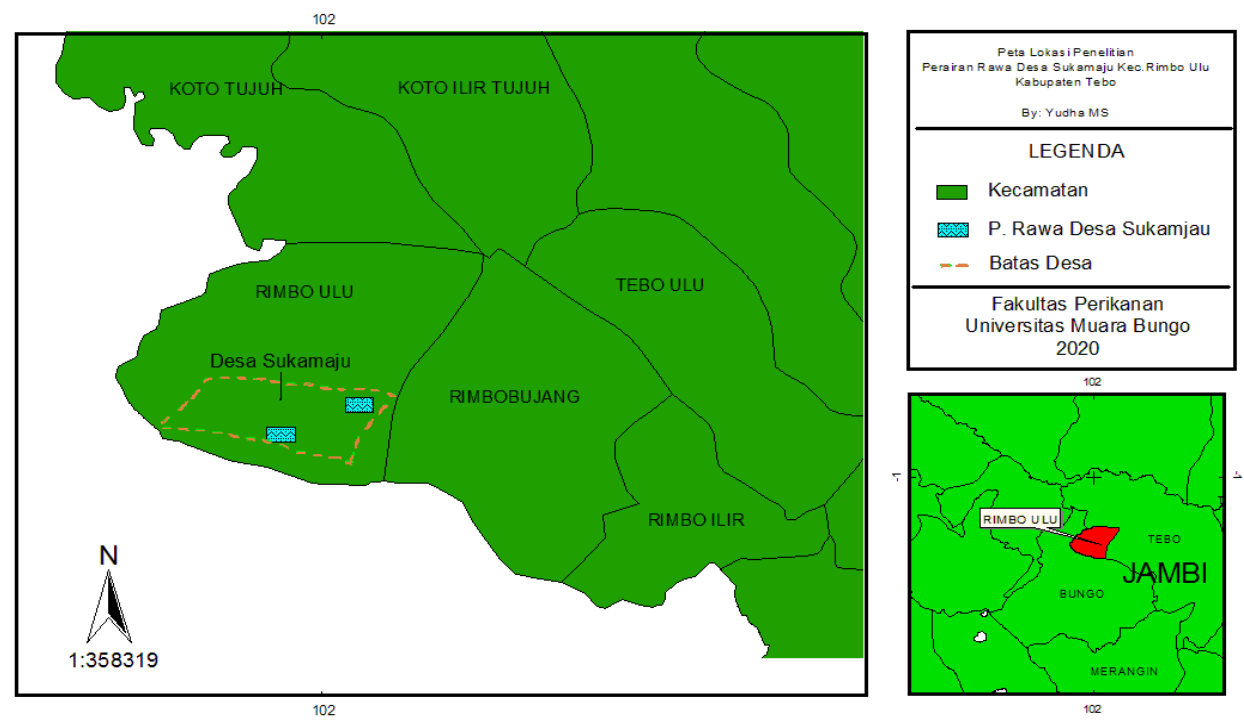

Gambar 1. Peta Lokasi Penelitian

\section{Metode dan Teknik Pengumpulan Data}

Metode yang digunakan pada penelitian ini yaitu metode eksperimental fishing. Data yang digunakan terdiri dari data primer dan data sekunder. Data primer diambil dengan melakukan operasi penangkapan ikan secara langsung dengan alat tangkap bubu kawat. Sedangkan data sekunder diambil dengan cara menelaah laporan atau tulisan yang relavan dari tinjauan pustaka baik dari perguruan tinggi, dinas perikanan dan lainnya.

\section{Prosedur Penelitian}

Penelitian ini memiliki prosedur kerja sebagai Berikut: a. Prosedur kerja pemasangan alat tangkap bubu kawat dengan 30 kali ulangan:

1. Menentukan lokasi yang akan dipasang bubu

2. Menyiapkan umpan yang akan digunakan

3. Menyiapkan alat tangkap bubu

4. Memasang umpan kedalam alat tangkap bubu

5. Pemasangan alat tangkap bubu (setting)

6. Pengangkatan alat tangkap bubu (hauling)

b. Prosedur kerja pengambilan sampel ikan hasil tangkapan dan proses pengukurannya:

1. Ikan hasil tangkapan dimasukan kedalam jerigen. 
2. Ikan diletakan di atas nampan ukur.

3. Ikan diukur panjang total (TL) satu persatu menggunakan mistar mulai ujung kepala hingga ke ujung ekor dan dicatat hasilnya (Gambar 2).
4. Kemudian ikan berat menggunakan timbangan digital dan dicatat hasilnya.

5. Selanjutnya dianalisa data yang diperoleh menggunakan microsoft office excel.

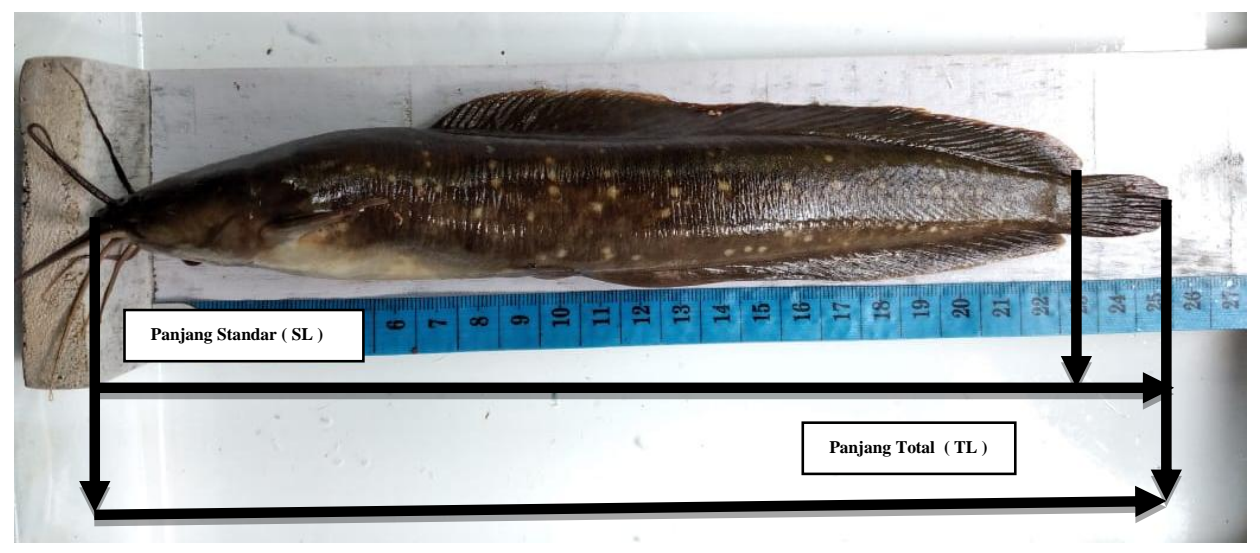

Gambar 2. Teknik Pengukuran Ikan Limbat

\section{Analisis Data}

\section{Analisis Hubungan Panjang dan Berat}

Untuk mencari hubungan antara panjang berat tubuh ikan digunakan persamaan meneurut (Effendie, 1997); (Kholis et al., 2018) sebagai berikut:

$$
\mathrm{W}=\mathrm{aLb}
$$

Keterangan :

$\mathrm{W}=$ berat tubuh ikan limbat $(\mathrm{g})$

$\mathrm{L}=$ panjang ikan limbat ( $\mathrm{mm})$

$\mathrm{a}$ dan $\mathrm{b}=$ konstanta

Nilai $b$ sebagai penduga hubungan antara panjang dan berat dengan kriteria :

Nilai $b=3$, ikan memiliki pola pertumbuhan isometrik (pertambahan berat seimbang dengan pertambahan panjang).
- Nilai b > 3, ikan memiliki pola pertumbuhan allometrik positif (pertambahan berat lebih cepat dari pertambahan panjang).

- Nilai $b<3$, ikan memiliki pola pertumbuhan allometrik negatif (pertambahan panjang lebih cepat dari pertambahan berat).

2. Analisis Faktor Kondisi

Faktor kondisi menunjukan keadaan baik dari ikan dilihat dari segi kapasitas biologis dan kondisi lingkungan ikan. Faktor kondisi dihitung dengan menggunakan sistem metrik berdasarkan hubungan panjang bobot ikan sampel. Jika pertambahan bobot seimbang dengan pertambahan panjang maka pertumbuhan ikan bersifat isometrik sehingga persamaan untuk menghitung faktor kondisi yaitu, (Effendie 2002); (Bidawi et al., 2017): 


$$
K F=\frac{10^{5} \mathrm{~W}}{\mathrm{~L}^{3}}
$$

Apabila pertumbuhan bersifat allometrik yakni pertambahan panjang dan pertambahan bobot tidak seimbang, maka persamaannya yaitu:

\section{HASIL DAN PEMBAHASAN} Komposisi Hasil Tangkapan Bubu Kawat

Komposisi hasil tangkapan bubu kawat yang dioperasikan sebanyak 30 kali pengulangan ini mendapat hasil tangkap sebanyak 5 spesies antara lain ikan limbat (Clarias nieuhofii), ikan

$$
K F=\frac{W}{a L^{b}}
$$

Keterangan :

$\mathrm{KF}=$ Faktor Kondisi

$\mathrm{W}=$ Bobot Ikan $(\mathrm{g})$

$\mathrm{L}=$ Panjang Total (mm)

sepat (Trichogaster trichopterus ), ikan bujuk (Channa lucius cuvier), ikan betok (Anabas testudineus ), dan (kepiting) yuyu (Parathelphusa convexa) dengan total hasil tangkapan 145 ekor. Untuk lebih jelasnya dapat dilihat pada (Gambar 3) berikut.

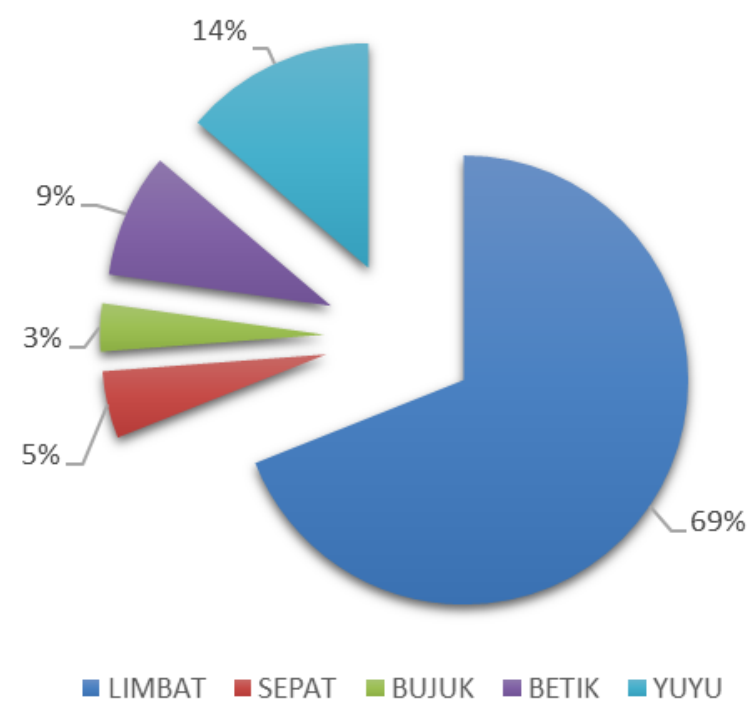

Gambar 3. Komposisi Hasil Tangkapan Bubu Kawat

Berdasarkan (Gambar 3) dapat diketahui bahwa komposisi hasil tangkapan yang diperoleh selama penelitian dengan 30 kali pengulangan sebanyak 5 spesies ikan. Hasil tangkapan didominasi ikan limbat (Clarias nieuhofii) yaitu $62 \%$ dengan jumlah 100 ekor, ikan sepat
(Trichogaster trichopterus) $5 \%$ dengan jumlah 7 ekor, ikan bujuk (Channa lucius cuvier) 3\% dengan jumlah 5 ekor, ikan betik (Anabas testudineus) 9\% dengan jumlah 13 ekor, dan (kepiting) yuyu (Parathelphusa convexa) 14\% dengan jumlah 20 ekor yang tertangkap pada 
alat tangkap bubu kawat di perairan rawa desa sukamaju.

Ikan limbat (Clarias nieuhofii) merupakan spesies ikan yang banyak tertangkap di perairan rawa desa sukamaju, sehingga dapat dikatakan bahwa perairan rawa merupakan habitat alami ikan limbat (Clarias nieuhofii). Menurut Suyanto (2004) habitat ikan limbat terdapat di semua perairan tawar dan tidak dapat dijumpai di perairan payau maupun asin. Ikan limbat hidup di perairan yang alirannya tidak terlalu deras atau perairan yang tenang seperti danau, waduk, rawa maupun suatu genangan kecil. Ikan limbat memiliki organ insang tambahan yang berfungsi untuk pengambilan oksigen dari udara

\section{Sebaran Panjang Ikan Limbat}

Berdasarkan hasil tangkapan menggunakan bubu kawat di perairan rawa desa sukamaju Kabapaten Tebo, didapatkan sebaran panjang ikan limbat yang tertangkap terbanyak yaitu pada bulan Juli sebanyak 24 ekor dengan sebaran panjang 160,5-240,5 mm. Sedangkan sebaran panjang ikan limbat terendah yaitu pada Bulan Agustus sebanyak 2 ekor dengan sebaran panjang 240,5-320,5 mm. Hampir semua sebaran panjang ikan limbat tertangkap pada bubu kawat, tetapi ikan limbat tidak tertangkap pada sebaran panjang 320,5-400,5 mm pada Bulan Agustus. Hal ini dapat diluar air, oleh karena itu ikan limbat tahan hidup di perairan yang airnya mengandung sedikit oksigen. Selain itu menurut Syafrialdi, (2020) menyatakan bahwa faktor suhu dan kedalaman air adalah faktor paling kuat dalam mempengaruhi ekologi ikan.

Komposisi hasil tangkapan didominasi oleh ikan limbat, hal ini diduga sangat erat dengan lokasi pemasangan (daerah penangkapan) dari alat tangkap bubu kawat yang merupakan tempat hidup ikan limbat. Menurut Pechsiri dan Vanichanon (2016) ikan limbat (Clarias nieuhofii) termasuk famili clariidae dari 3 populasi liar di hutan rawa dan gambut di Thailand Selatan.

terjadi kemungkinan adanya pengaruh dari faktor cuaca, lingkungan penangkapan atau faktor lainnya, sehingga ikan limbat tidak tertangkap pada sebaran panjang tersebut. Perbedaan variasi sebaran panjang kemungkinan besar disebabkan juga oleh ukuran alat tangkap dan efek penanganan ikan selama penelitian (Hossain, 2010). Selain itu, kualitas geografis, ekologi dan parameter air pada habitat ikan sangat menentukan perbedaan morfologi dan ukurannya (Aryani et al., 2017; Roesma dan Syandri, 2020). Lebih jelas sebaran panjang ikan limbat yang tertangkap dapat dilihat pada (Gambar 4). 


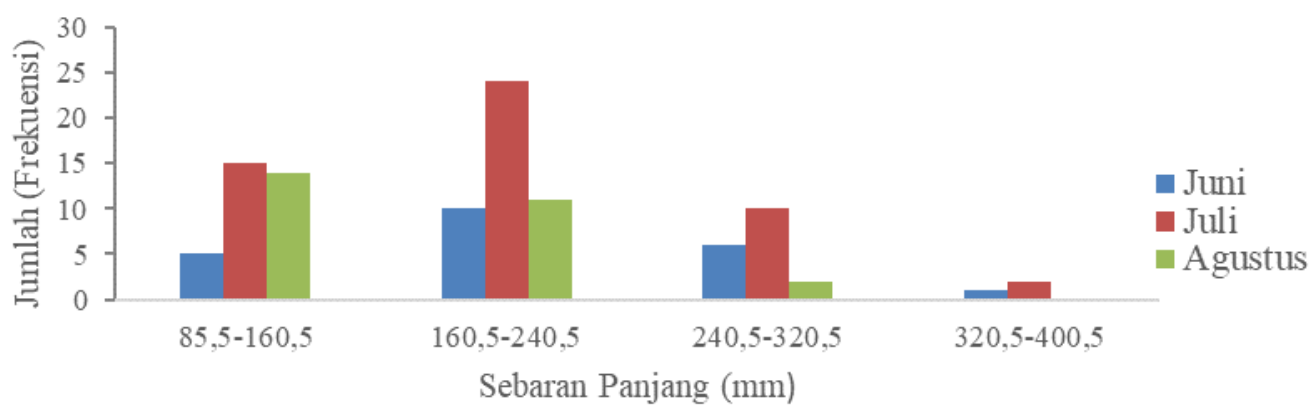

Gambar 4. Sebaran Panjang Ikan Limbat di Perairan Rawa Desa Sukamaju Kabupaten Tebo

Hubungan Panjang Berat Ikan Limbat

Selama penelitian di perairan rawa desa suka maju hasil tangkapan ikan limbat berjumlah total sebanyak 100 ekor, terdiri atas ikan jantan sebanyak 45 ekor dan ikan betina 55 ekor. Berdasarkan hasil tangkapan ikan limbat yang diperoleh, sebaran ikan limbat betina terbanyak tertangkap pada bulan Juli dengan jumlah sebanyak 28 ekor dan terendah pada bulan Juni sebanyak 11 ekor. Sedangkan untuk sebaran ikan limbat jantan terbanyak tertangkap pada bulan Juli dengan jumlah sebanyak 23 ekor dan terendah pada bulan Juni sebanyak 11 ekor.

Menurut Roesma dan Syandri (2020) populasi ikan betina lebih banyak dibandingkan ikan jantan hal itu memiliki banyak kemungkinan seperti: perbedaan rasio jenis kelamin, kegiatan masyarakat di bantaran sungai dan di sepanjang sungai. Perbedaan aktivitas yang terjadi diperkirakan berdampak pada kualitas ikan, komposisi makanan, perubahan ketinggian air termasuk perjalanan sedimen yang pada akhirnya mempengaruhi metabolisme ikan dan biologisnya. Aktivitas tersebut berdampak juga pada habitat dan tidak selektifnya penangkapan ikan. Oleh karena itu, perlu adanya standarisasi ukuran sampling, kedalaman air, musim kawin dan biologi ikan (Roesma dan Syandri, 2020; Sekitar et al., 2015). Untuk lebih jelas sebaran jenis kelamin ikan limbat dapat dilihat pada (Gambar 5).

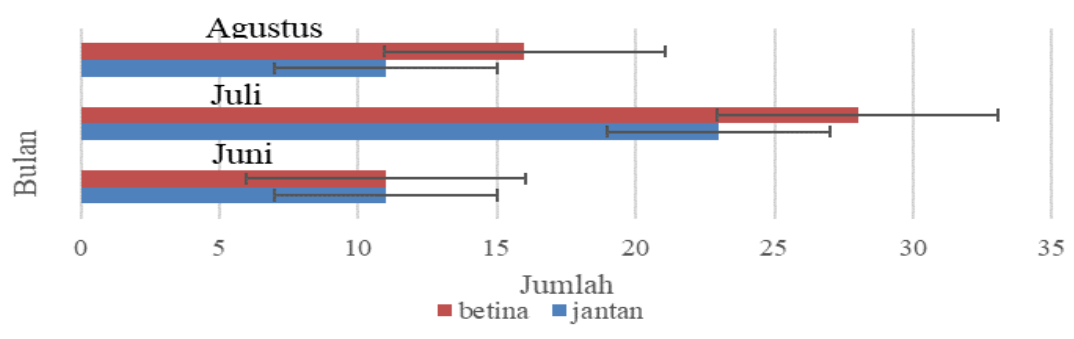

Gambar 5. Sebaran Jenis Kelamin Ikan Limbat 
Hubungan panjang dan berat ikan limbat didapatkan persamaan regresi yaitu y $=2,3279 x-8,0692$. Artinya setiap penambahan panjang ikan limbat sebesar $23 \mathrm{~mm}$ berat akan bertambah sebesar -8.1 g. Hubungan panjang berat ikan limbat diketahui kuat hubungannya karena memiliki $\mathrm{R}^{2}$ koefisien determinasi mendekati $1, \mathrm{R}^{2}$ $=0.7923$ artinya nilai tersebut menunjukan bahwa hubungan panjang berat tubuh ikan limbat memiliki korelasi yang kuat. Lebih jelas regresi panjang dan berat ikan limbat dapat dilihat pada (Gambar 6).

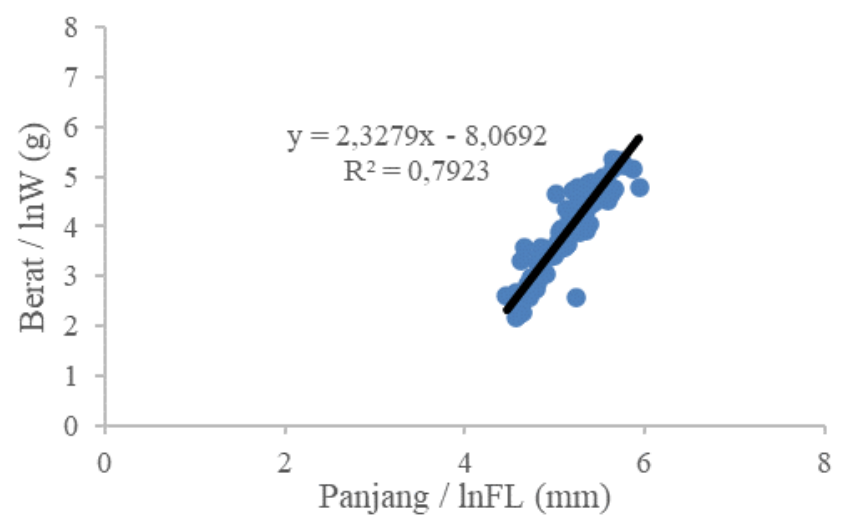

Gambar 6. Regresi Panjang dan Berat Ikan Limbat

\section{Pola Pertumbuhan Ikan Limbat}

Pola pertumbuhan ikan limbat didapatkan persamaan $\mathrm{W}=13.405 \mathrm{~L}$ 165.83, yang menunjukan bahwa nilai b ikan limbat yaitu 2,32786 (b < 3) artinya pola pertumbuhan ikan limbat bersifat allometrik negatif, dimana pertumbuhan panjang lebih cepat dibandingkan pertumbuhan berat. Menurut Kusmini et al., (2018) pertumbuhan ikan erat kaitannya dengan hubungan panjang dan berat (bobot), berdasarkan pengamatan dan pengukuran secara fisik parameter ini dapat menggambarkan kondisi ikan berukuran kecil, sedang atau besar (Ibrahim et al., 2018).

Menurut Effendi (2002), pertumbuhan dipengaruhi oleh beberapa faktor yaitu faktor dalam dan luar. Faktor dalam umumnya adalah faktor yang sukar dikontrol, diantaranya keturunan, jenis kelamin, umur, parasit, dan penyakit. Sebaliknya, faktor luar yang utama mempengaruhi pertumbuhan adalah makanan dan suhu perairan. Hal itu sama halnya menurut Ozaydin et al., (2007); Cherif et al., (2008); Sahoo et al., (2012); Roesma dan Syandri, (2020) perbedaan pola pertumbuhan dapat disebabkan oleh panjang ikan, ukuran kematangan gonad dan isi lambung, serta perbedaan habitat. Faktor tingkat kematangan gonad ikan berkorelasi positif dengan sifat fisika kimia air, ketersediaan pangan dan perbedaan umur (Rajagopal et al., 2008; Gupta, 2014; Nehemia et al., 2012; Hasri et al., 2017) serta termasuk kondisi perairan untuk pemijahan, seperti arus dan substrat air (Syandri et al., 2013). Lebih jelas pola pertumbuhan ikan limbat dapat dilihat pada (Gambar 7). 


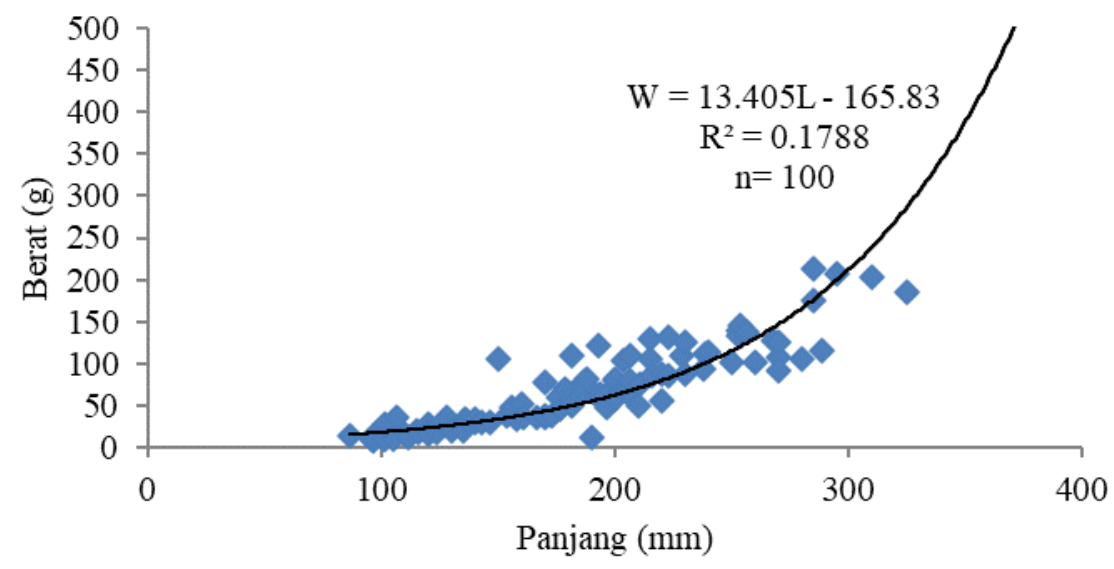

Gambar 7. Hubungan panjang dan berat ikan limbat di Perairan Rawa Desa Sukamaju Kabupaten Tebo

\section{Faktor Kondisi Ikan Limbat}

Selain pola pertumbuhan, faktor kondisi juga menjadi bagian dari parameter pertumbuhan. Faktor kondisi menunjukkan jika ikan masuk kondisi baik atau buruk, dalam hal kemampuan fisik untuk bertahan hidup dan reproduksi (Roesma dan Syandri, 2020). Faktor kondisi menggambarkan kemontokan ikan yang dinyatakan berdasarkan data panjang dan berat. Hasil perhitungan nilai faktor kondisi didapatkan sebesar 1,01 yang menunjukan kondisi ikan limbat di perairan rawa desa sukamaju Kabupaten Tebo masih kategori baik. Hal itu dapat dilihat dari sebaran pada Bulan Juni $\mathrm{K}=0,92$, Bulan Juli $\mathrm{K}=1,01$, dan Bulan Agustus K=1,10.

Hasil ini sesuai dengan
pernyataan

Damayanti (2013), yaitu nilai K yang berkisar antara 1-3 mengindikasikan keadaan yang baik. Ikan limbat tergolong ikan yang bentuk badannya pipih, karena faktor kondisinya diatas angka 1 dan tidak melebihi angka 3. Nilai faktor kondisi ikan limbat di suatu perairan bervariasi. Variasi nilai faktor kondisi (K) tergantung pada makanan, umur, jenis kelamin dan kematangan gonad (Effendie, 2002). Untuk lebih jelasnya sebaran nilai faktor kondisi ikan limbat dapat pada (Gambar 8).

Faktor kondisi dapat naik dan turun karena merupakan indikasi dari musim pemijahan bagi ikan, khususnya ikan-ikan betina (Effendie 2002). Nilai faktor kondisi akan meningkat menjelang puncak pemijahan dan menurun setelah pemijahan (Rahardjo dan Simanjuntak, 2008; Ibrahim et al., 2018), hal ini dikarenakan sumber energi utama digunakan untuk perkembangan gonad dan pemijahan (Lizama et al., 2002). 


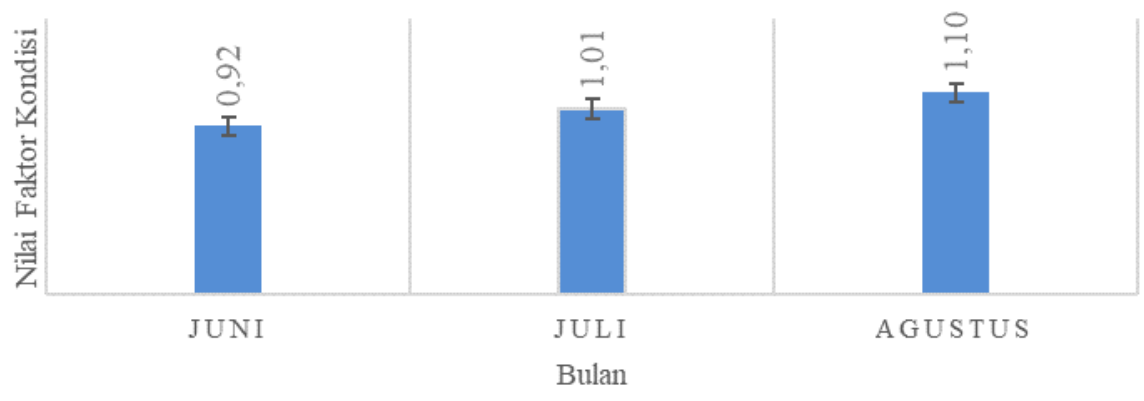

Gambar 8. Sebaran Nilai Faktor Kondisi Ikan Limbat

Perbedaan faktor kondisi (Gambar 8) ini berkaitan dengan interaksi biologis yang melibatkan persaingan intra-spesifik untuk makanan, jenis kelamin, jarak antar spesies, intensitas makan, perkembangan gonad dan ketersediaan pangan (Syafrialdi, 2020). Selain itu menurut Roesma dan Syandri, (2020) jumlah populasi dapat terus menurun karena kegiatan penangkapan ikan yang tidak selektif. Fluktuasi faktor kondisi juga disebabkan oleh kesesuaian dan ketersediaan pangan pada waktu tertentu, intensitas pemberian pakan berhubungan dengan proses perkembangan gonad ikan (Mathialagan et al., 2014; Jewel et al., 2019).

Menjaga ketersediaan ikan limbat diperlukan adanya pengelolaan terhadap sumberdaya ikan ini. Salah

\section{KESIMPULAN DAN SARAN}

Kesimpulan

Hasil penelitian ini dapat disimpulkan bahwa ikan limbat (Clarias niuehofii) memiliki pola pertumbuhan allometrik negatif, dimana pertumbuhan panjang lebih cepat daripada pertumbuhan berat. Sedangkan faktor kondisi didapatkan nilai $\mathrm{K}=1,01$ yang artinya ikan limbat yang tertangkap dalam kondisi baik. satu informasi pengelolaan yang dibutuhkan yaitu pola pertumbuhan dan kondisi ikan di perairan agar dapat menduga musim pemijahan ikan. Hal ini akan berpengaruh terhadap sumberdaya ikan limbat yang ada di perairan rawa desa sukamaju Kabupaten Tebo.

Berdasarkan penelitian kondisi ikan limbat dalam keadaan baik dan kemungkinan pada saat penelitian ikan limbat baru akan melakukan pemijahan. Untuk mempertahankan keberlanjutan populasi ikan diperlukan adanya penerapan pengaturan, sehingga bentuk pengelolaan yang dapat dilakukan yakni penutupan musim penangkapan pada saat puncak pemijahan. Hal ini berkaitan dengan kelestarian dan kelangsungan sumberdaya ikan limbat di daerah perairan rawa tersebut.

\section{Saran}

Sebagai saran pada penelitian ini dapat dilakukan penelitian lanjutan untuk menentukan kematangan gonad, musim pemijahan, dan musim penangkapan. Selain itu diharapkan juga masyarakat menggunakan alat tangkap yang ramah lingkungan. 


\section{DAFTAR PUSTAKA}

Aryani, N., Hasibuan, S., Mardiah, A., \& Syandri, H. (2017). Morphometric Characteristics of Asian Catfish, Hemibagrus wyckii (Bleeker, 1858)(Bagridae), from the Riau Province of Indonesia. Pakistan journal of biological sciences: PJBS, 20(8), 382-389.

Bidawi, B. M., Desrita, D., \& Yunasfi, Y. (2017). Hubungan panjang berat dan faktor kondisi ikan belodok (Famili: Gobiidae) pada Ekosistem Mangrove di Desa Pulau Sembilan Kabupaten Langkat Provinsi Sumatera Utara. DEPIK Jurnal Ilmu-Ilmu Perairan, Pesisir dan Perikanan, 6(3), 228-234.

Brandt, V. A. 1984. Fish Catching Methods of The World. Fishing News Book Ltd. London. 418p.

Cherif, M., R. Zarrad, H. Gharbi, H. Missaoui and O. Jarboui, (2008). Length-weight relationships for 11 fish species from the Gulf of Tunis (SW Mediterranean Sea, Tunisia). Pan-Am. J. Aquatic Sci., 3: 1-5.

Damayanti. (2013). Hubungan Panjang Bobot dan Faktor Kondisi Ikan Layang (Decapterus macrosoma Bleeker, 1851) Tertangkap di Perairan Teluk Bone (Skripsi). Tidak di Publikasikan, Fakultas Ilmu Kelautan dan Perikanan. Universitas Hasanuddin. Makasar.

Effendie, M. I. (1997). Biologi perikanan. Yayasan Pustaka Nusatama. Yogyakarta, 163.

Effendie, M. I. (2002). Biologi Perikanan (Revisi)(p. 163).
Bogor: Yayasan Pustaka Nusatama.

Fatioye, O.O., \& Oluajo, O.A. (2005). Length-Weight Relationships Of Five Fish Species In Epe Lagoon, Nigeria. African Journal of Biotechnology. 4(7): 749-751.

Gupta, S. (2014). Morphology, growth pattern, feeding and reproductive biology of Mystus gulio (Hamilton-Buchanan, 1822)(Siluriformes: Bagridae). International Journal of Aquatic Biology, 2(4), 201-205.

Hasri, I., \& Kamal, M. M. (2017). Pertumbuhan dan laju eksploitasi ikan endemik Rasbora tawarensis (Weber \& de Beaufort, 1916) di Danau Laut Tawar, Aceh Tengah [Growth and exploitation rate of endemic fish Rasbora tawarensis (Weber and de Beaufort, 1916) at Laut Tawar Lake in Central Aceh]. Jurnal Iktiologi Indonesia, 11(1), 21-28.

Hossain, M. Y. (2010). Morphometric relationships of length-weight and length-length of four Cyprinid small indigenous fish species from the Padma River (NW Bangladesh). Turkish Journal of Fisheries and Aquatic Sciences, 10(1), 131-134.

Https://id.wikipedia.org/wiki/Limbat [diakses pada tanggal 13 April 2020 Pukul 22.49 WIB].

Ibrahim, P. S., \& Setyobudiandi, I. (2018). Length-weight Relationship and Condition Factor of Yellowstripe Scads Selaroides Leptolepis in Sunda Strait. Jurnal Ilmu dan Teknologi Kelautan Tropis, 9(2), 577-584. 
Jewel, M. A. S., Haque, M. A., Ferdous, M. S., Khatun, M. S., \& Akter, S. (2019). Research Article Length-weight Relationships and Condition Factors of Cirrhinus reba (Hamilton, 1822) in Padma River, Bangladesh.

Kholis, M. N., \& Wahju, R. I. (2018). Struktur Ukuran Dan Hubungan Panjang Berat Ikan Kurau Di Pulau Bengkalis. ALBACORE Jurnal Penelitian Perikanan Laut, 2(2), 197-208.

Kusmini, I. I., Kristanto, A. H., Subagja, J., Prakoso, V. A., \& Putri, F. P. (2018). Respons Dan Pola Pertumbuhan Benih Ikan Baung (Hemibagrus nemurus) Dari Tiga Generasi Dipelihara Pada Wadah Budidaya Yang Berbeda. Jurnal Riset Akuakultur, 13(3), 201-211.

Lizama, M. D. L. A. P., \& Ambrosio, A. M. (2002). Condition factor in nine species of fish of the Characidae family in the upper Paraná river floodplain, Brazil. Brazilian Journal of Biology, 62(1), 113-124.

Martasuganda, S. 2005. Serial Alat Tangkap Gillnet, Setnet, Trap. Jilid I. Bogor.

Mathialagan, R., Sivakumar, R., Rajasekaran, N., \& Chandrasekar, S. (2014). Length-frequency distribution and length-weight relationship of reba carp Cirrhinus reba (Hamilton, 1822 Cypriniformes: Cyprinidae) from Lower Anicut, Tamil Nadu, India. Inter J Fish Aquat Studies, 2, 115-125.

Nehemia, A., Maganira, J. D., \& Rumisha, C. (2012). Length-
Weight relationship and condition factor of tilapia species grown in marine and fresh water ponds. Agriculture and Biology Journal of North America, 3(3), 117-124.

Özaydın, O., Uçkun, D., Akalın, S., Leblebici, S., \& Tosunoğlu, Z. (2007). Length-weight relationships of fishes captured from Izmir Bay, Central Aegean Sea. Journal of Applied Ichthyology, 23(6), 695-696.

Pechsiri, J., \& Vanichanon, A. (2016). Genetic Diversity in Slender Walking Catfish (Clarias nieuhofii) Populations: Implications for Population Management. Walailak Journal of Science and Technology (WJST), 13(7), 511-519.

Rahardjo, M. F., \& Simanjuntak, C. P. (2008). Hubungan panjang bobot dan faktor kondisi ikan tetet, Johnius belangerii Cuvier (Pisces: Sciaenidae) di perairan pantai Mayangan, Jawa Barat. Jurnal Ilmu-ilmu Perairan dan Perikanan Indonesia, 15(2), 135140.

Rajagopal, B., \& Davidar, P. (2008). On the population and breeding aspects of catfish in fresh water wetlands of Tamilnadu, Peninsular India. Electronic Journal of Ichthyology, 1, 18-30.

Roesma, I., \& Syandri, H. (2020). Length-Weight Relationship and Condition Factor of Two-Spot Catfish (Mystus nigriceps [Valenciennes, 1840])(Pisces, Bagridae), from Kampar Kanan River and Kampar Kiri River in Indonesia. Pakistan Journal of 
Biological Sciences:

PJBS, 23(12), 1636-1642.

Sahoo, D. K., Karna, S. K., \& Panda, S. (2012). Length weight relationship and growth estimation of Mugil cephalus (Linnaeus, 1758) in the Chilika Lagoon, Orissa, India. Journal of Experimental Biological Sciences, 3(4), 700-705.

Sekitar, P. K. A., Hamid, M., Mansor, M. a. s. h. h. o. r., \& Nor, S. A. M. (2015). Length-weight relationship and condition factor of fish populations in Temengor Reservoir: Indication of environmental health. Sains Malaysiana, 44(1), 61-66.

Smith, K.M.M. (1996). Length-Weight Relationships Of Fishes In A Diverse Tropical Freshwater Cunnunity Sabah, Malaysia. Journal of Fish Biology (49): 731- 734.

Suyanto, N. S. R. (2004). Budidaya Ikan Lele (ed. Revisis). Niaga Swadaya.

Syafrialdi, S. (2020). Variasi Genetik dan Bioekologi Spesies Mystus nigriceps (Valenciennes 1840, Bagridae) Dihabitat Perairan Berbeda dalam Domestikasi (Doctoral dissertation, Universitas Andalas).

Syandri, H., \& Azrita, A. N. (2013). Size distribution, reproduction and spawning habitat of Bilih fish ((Mystacoleucus padangensis Blkr) in Lake Singkarak. Bawal, 5(1), 1-8. 